Acta Protozool. (2019) 58: 25-29

www.ejournals.eu/Acta-Protozoologica doi:10.4467/16890027AP.19.006.10837

PROTOZOOLOGICA

Short communication

\title{
Evidence of Stress Recovery in Free-Living Ciliate Colpoda cucullus: The Repair Capability of Resting Cysts to Damage Caused by Gamma Irradiation
}

\author{
Yoichiro SOGAME, Ryota SAITO, Ryota KOIZUMI, Taiga SHIMIZU, Taiki ONO
}

National Institute of Technology, Fukushima College, Iwaki, Fukushima Japan

\begin{abstract}
In this study, we report that the unicellular free-living protist Colpoda cucullus in the resting cyst (cryptobiosis) repairs stress damage. We previously demonstrated that resting cysts of Colpoda cucullus have extreme tolerance to gamma irradiation and can revert to vegetative cells after irradiation. Such irradiated cysts gradually excyst, suggesting that stress repair mechanisms are active during excystment or in the resting cyst. Herein we provide bioassay evidence that the rate of excystment of irradiated cysts is elevated by subsequent incubation, thereby indicating that cells injured by gamma irradiation can repair themselves in the resting cyst, whereas irradiated dry cysts cannot.
\end{abstract}

Key words: Stress recovery, Colpoda, Cryptobiosis, Resting cyst, Gamma irradiation.

\section{INTRODUCTION}

Cryptobiosis is a biological state in which the metabolic processes of an organism become barely measurable or reversibly cease and thus the organisms show no visible signs of life (Keilin 1959, Clegg 2001). This biological state is widely observed in both prokaryotic and eukaryotic microorganisms, including bacteria (bacterial spore), fungi (conidia and spores), and protozoa (resting cysts) (Gutierrez et al. 1990). Some ciliates form resting cysts when environmental condition become adverse (Veni and Rosati 2011). There is virtu-

Address for correspondence: Yoichiro Sogame, National Institute of Technology, Fukushima College, 30 Nagao Tairakamiarakawa, Iwaki, Fukushima 970-8034 Japan; E-mail: sogame@fukushimanct.ac.jp; TEL: +81-246-46-0875 ally no metabolic activity in resting cysts, and they can remain stable for long periods of time (Gutierrez et al. 1990). Hence, the formation of cysts, called encystment, represents a strategy for protists against several environmental stresses (Gutierrez et al. 2001).

The soil ciliate species of genus Colpoda form resting cysts in response to environmental stresses. The process of encystment is accompanied by a drastic morphogenic changes, including formation of the cyst wall (Gutiérrez et al. 2003). Cyst-specific structures help the organism tolerate stresses such as starvation (Gutiérrez et al. 2001), desiccation (Taylor and Stickland 1936), freezing (Uspenskaya and Lozina-Lozinski 1979), high and low temperature (Taylor and Stickland 1936), ultraviolet irradiation (Uspenskaya and Lozina-Lozinski 1979), and acid (Sogame et al. 2011). In addition, we recently demonstrated that Colpoda resting cysts have 
extreme tolerance to gamma irradiation (Saito et al., submitted).

In general, gamma rays affect microorganisms directly, but can also affect them indirectly (Jung et al. 2017). Irradiated cells are penetrated by photons (Richer et al. 2016), which interact with biological molecules directly (Close et al. 2013) and destroy them. Gamma rays also harm cells indirectly through the radiolysis of water, producing reactive oxygen species (ROS) that damage nucleic acids, proteins, and lipids (Halliwell and Gteridge 1999, Azzam et al. 2012, Close et al. 2013). Organisms deal with ROS stress by developing cell repair mechanisms. For example, the RAD51 protein family was reported to be involved in the repair of DNA molecules (Roca et al. 1997), and the expression of RAD51 in Tetrahymena thermophila was reported to be induced by UV irradiation (Campbell and Romero 1998).

We previously showed that irradiated Colpoda cysts revert gradually to vegetative cells after irradiation (Saito et al., submitted), suggesting that cell injuries caused by irradiation are repaired in the resting cyst and/or excystic phase. Cell repair after irradiation has been reported in the hyperthermophilic archaeon Phyrococcus furiosus in the active state under favorable culture conditions (DiRggiero et al. 1997). However, the information on the ability of resting ciliate cysts to recover from damage are still absent. In this study, we report bioassay evidence indicating that irradiated cells in the resting cyst can repair injuries.

\section{MATERIALS AND METHODS}

Colpoda cucullus R2TTYS (Saito et al., submitted) was cultured in culture medium $[0.05 \%(\mathrm{w} / \mathrm{w})$ of an infusion of dried wheat leaves] inoculated with the bacterial strain Klebsiella pneumoniae NBRC13277 as a food source.

Encystment and excystment were induced as previously described (Sogame et al. 2011). Encystment was induced by suspending cells at high cell density $(>10,000$ cells $/ \mathrm{mL})$ in encystment-inducing medium [1 mM Tris- $\mathrm{HCl}$ ( $\mathrm{pH}$ 7.2), $0.1 \mathrm{mM} \mathrm{CaCl}_{2}$ ]. Excystment was induced by replacing this medium with excystmentinducing medium $[0.2 \%(\mathrm{w} / \mathrm{v})$ infusion of dried wheat leaves].

Vegetative cell samples were prepared 3-6 h after excystment by transfer to Petri dishes at low cell density (about 1,000 cells $/ \mathrm{mL}$ ) to prevent the induction of encystment. Wet cyst samples were prepared by transferring cells to a Petri dish containing encystment-inducing medium and incubating for more than 1 week. Dry cyst samples were prepared by air-drying the wet cyst samples for 1 week.

Cysts in Petri dishes were irradiated with gamma rays at 4000 Gy using a RE2022 (Toshiba, Japan) with cobalt 60 (radioactivity, about $34 \mathrm{TBq}$ ) as the radiation source. The gamma ray dose was calculated as follows: $\log \mathrm{Y}(\mathrm{Gy} / \mathrm{h})=\mathrm{A} \log \times \mathrm{B}(\mathrm{cm})$, where $\mathrm{A}$ is the systematic value 3.154 , and $B$ is the distance of the sample to the radiation source $(\mathrm{cm})$. Six replicas for each sample were prepared. After irradiation, cysts were induced to excyst and the excystment rate was estimated as follows: excystment rate $(\%)=$ (number of excysted cells / number of excysted and non-excysted cells $) \times 100$. Excysted and non-excysted cells ( $>100$ cells) were directly counted under an optical microscope (Stemi 305, ZEISS). The significance of differences among samples was evaluated by the Mann-Whitney U test.

\section{RESULTS AND DISCUSSION}

In this study, cell damage caused by irradiation was repaired in the resting cysts. Evidence for this conclusion is shown in Fig. 1: wet cysts irradiated with 4000 Gy recovered their ability to revert to vegetative cells following incubation for $12 \mathrm{~h}$ (Fig. 1A) whereas irradiated dry cysts did not (Fig. 1B).

No cysts underwent excystment if excystment was not induced; $0 \mathrm{~h}$ (Fig. 1A) [i.e., all samples did not excyst $(0 \pm 0 \%)]$. In contrast, at $3 \mathrm{~h}$ after inducing excystment, $88.77 \pm 1.95 \%$ of non-irradiated wet cysts excysted whereas irradiated wet cysts did not excyst (Fig. $1 \mathrm{~A} ; 3 \mathrm{~h}$ ). These results indicate that the irradiated cysts are damaged by gamma irradiation. Irradiated cells were penetrated by photons and were damaged due to the radiolysis of water, producing reactive oxygen species (ROS) that damage nucleic acids, proteins, and lipids (Imlay and Linn 1988, Halliwell and Gteridge 1999, Azzam et al. 2012, Close et al. 2013). Such damage to biological molecules results in serious damage to protist cells (Slaveykova et al. 2016). In addition, irradiated cells underwent necrotic or apoptotic cell death caused by ROS (Ryter et al. 2007). Gamma irradiation may damage Colpoda cells by an unspecified mechanism, thereby suppressing the rate of excystment.

On the other hand, when irradiated wet cysts are induced to excyst subsequent to incubation for $12 \mathrm{~h}$ (irradiated-incubated cysts), the rate of excystment is increased $(50.81 \pm 11.54 \%)$ at $3 \mathrm{~h}$ after the induction of excystment (Fig. 1A; $3 \mathrm{~h}$ ). These results provide evidence that the ability of cells to excyst was repaired during the $12 \mathrm{~h}$ incubation period of the resting cysts, indicating that cell repair mechanisms operate during the resting cyst stage. As mentioned above, gamma rays generally cause serious damage to DNA both directly and indirectly. Gamma irradiation activates RAD51, a protein involved in the repair of DNA damage in 
(A)

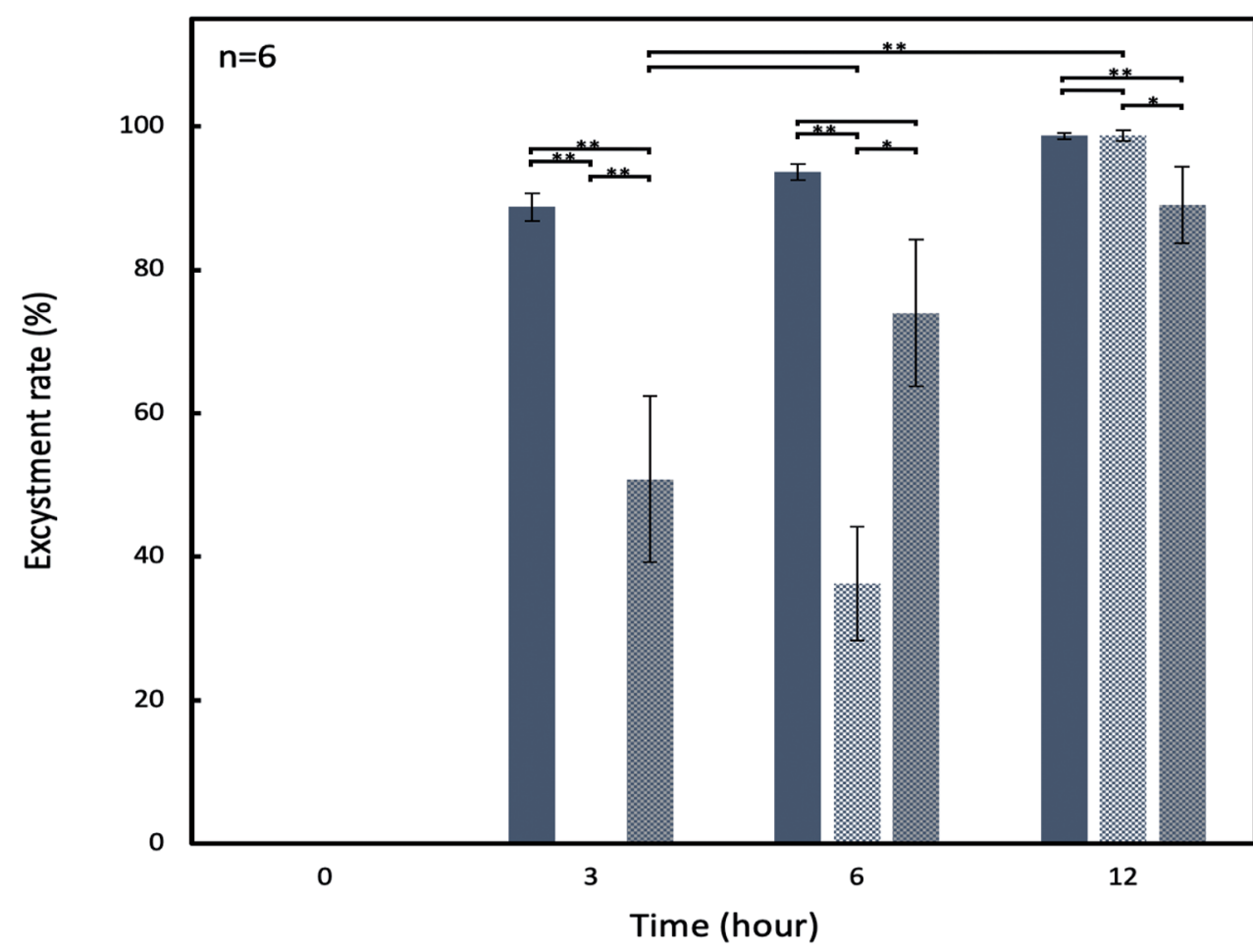

Non-irradiated
Irradiated
Irradiated-
incubated

(B)

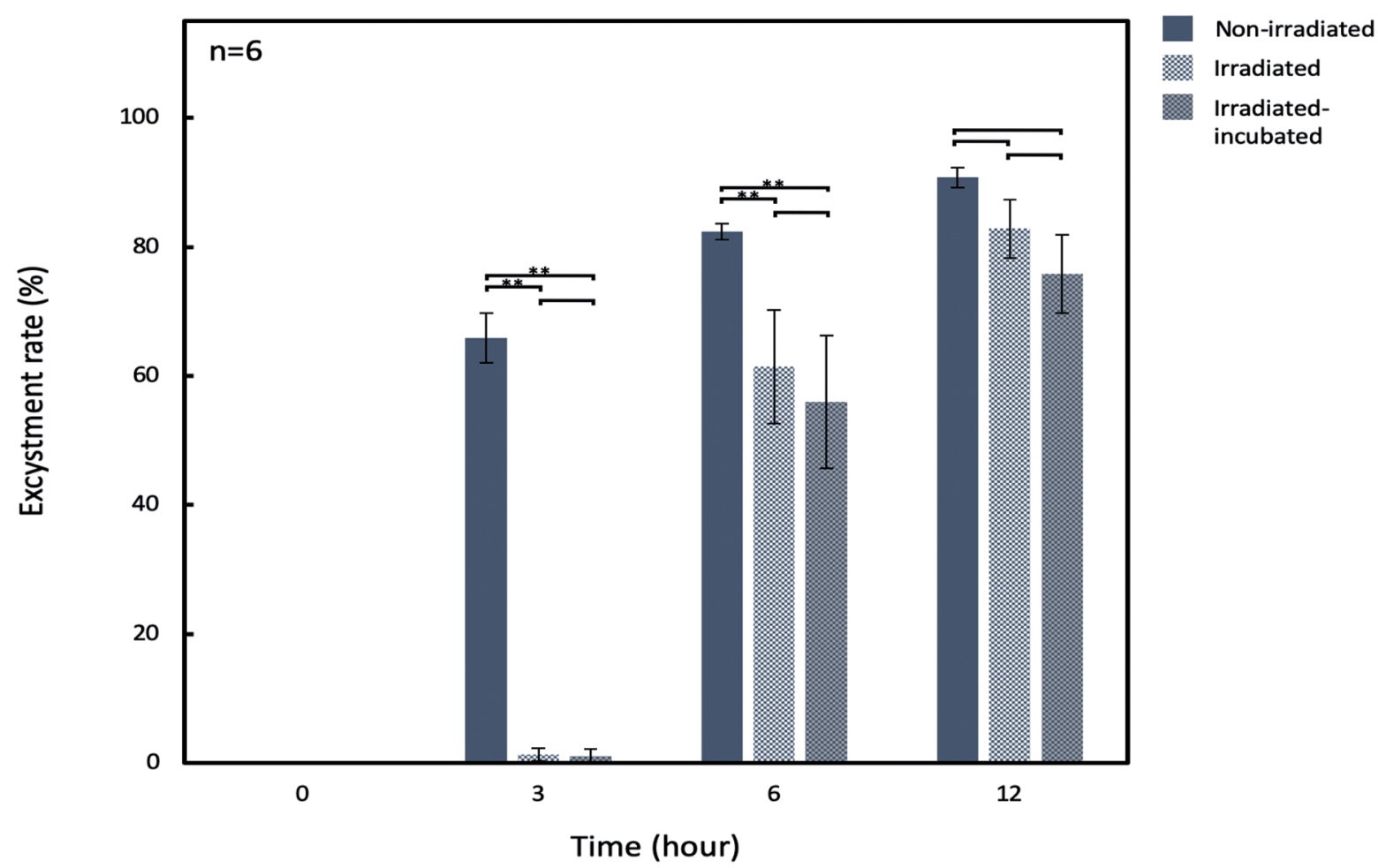

Fig. 1. Excystment assay of Colpoda wet cysts (A) and dry cysts (B). 'Non-irradiated' indicates non-irradiated cysts; 'irradiated' indicates cysts irradiated at $4000 \mathrm{~Gy}$, and 'irradiated-incubated' indicates cysts irradiated at $4000 \mathrm{~Gy}$ and incubated for 12 hours before the induction of excystment. Time indicates the number of hours after the induction of excystment. Columns and attached bars correspond to the means and standard errors, respectively, of six measurements. Asterisks and double asterisks represent significant differences at $\mathrm{p}<0.05$ and $\mathrm{p}<0.01$ (Mann-Whitney U test), respectively. 
T. thermophila (Campbell and Romero 1998). Factors such as RAD51 might also be activated in resting Colpoda cysts. Further experiments including western blot and qPCR analyses, will be conducted in the future to provide molecular evidence for the underlying the repair mechanism. In addition, it will be also interesting works to investigate the relationship between the age (condition) of a cyst and the level of cell repair activity, because the encysting cells reported to retain their metabolic activity (Funadani et al. 2010, Sogame et al. 2014), whereas they have less tolerance to acids than mature cysts (Sogame et al. 2011).

Notably, the rate of excystment of irradiated and incubated cysts at $3 \mathrm{~h}$ after the induction of excystment tended to be higher than that of irradiated cysts at $6 \mathrm{~h}$ after the induction of excystment $(36.24 \pm 7.96 \%)$ $(p>0.05)$. This result suggests that resting cysts retain the ability to repair cell damage despite nearly undetectable levels of metabolic activity, as reflected by the lack of mitochondrial membrane potential in resting cysts (Funatani et al. 2010, Sogame et al. 2014). It is possible that the inactive metabolism of cysts could be activated by stress (gamma irradiation), leading to the repair of damage. On the other hand, the rate of excystment at $3 \mathrm{~h}$ after the induction of excystment of irradiated and incubated cysts was significantly lower than that of irradiated cysts at $12 \mathrm{~h}$ after the induction of excystment $(98.76 \pm 0.73 \%)(p<0.01)$ (Fig. 1A). These results suggest that the activity of cell repair of resting cysts is lower than that of cells in the excysting stage. Subsequent to inducing excystment, cell metabolic activity is recovered immediately, as suggested by a report that proteins such as dead box RNA helicase are expressed $10 \mathrm{~min}$ after the induction of excystment (Sogame et al. 2013). Hence, cell repair might be activated in excysting cells. At $6 \mathrm{~h}$ after the induction of excystment, the rate of excystment of non-irradiated cysts was elevated (93.63\%) and the irradiated cysts had started to excyst $(36.24 \pm 7.96 \%)$ (Fig. 1A; $6 \mathrm{~h}$ ). The rate of excystment of irradiatedincubated cysts was also elevated (73.98 $\pm 10.25 \%)$, as described above (Fig. 1A; 6 h). The rates of excystment of non-irradiated cysts and irradiated-incubated cysts were significantly higher than that of irradiated cysts ( $p<0.01$ and $\mathrm{p}<0.05$, respectively), whereas there was no significant difference between non-irradiated cysts and irradiated-incubated cysts $(p>0.05)$ (Fig. 1A; 6 h). These results also indicate that repair mechanism were activated in resting cysts.
At $12 \mathrm{~h}$ after the induction of excystment, the excystment rates of non-irradiated cysts, irradiated cysts, and irradiated-incubated cysts were $98.66 \pm 0.39 \%, 98.76$ $\pm 0.73 \%$, and $89.03 \pm 5.33 \%$, respectively (Fig. 1A; $12 \mathrm{~h}$ ). Consequently, most cysts excysted, regardless of whether or not they were irradiated and incubated. The excystment rate of irradiated-incubated cysts was significantly lower than that of non-irradiated cysts and irradiated cysts $(\mathrm{p}<0.05$ and $\mathrm{p}<0.01$, respectively), whereas there was no difference between the excystment rate of non-irradiated and irradiated cysts (Fig. $1 \mathrm{~A} ; 12 \mathrm{~h})$. These results suggest that some cells in the resting cyst were unable to completely repair the damage caused by irradiation and died, perhaps because cell repair activity in the resting cyst may be lower than in the excystment state.

Non-irradiated dry cysts, irradiated dry cysts, and irradiated-incubated dry cysts were $65.85 \pm 3.85 \%, 1.29$ $\pm 0.99 \%$, and $75.79 \pm 6.12 \%$ excysted, respectively, $3 \mathrm{~h}$ after the induction of excystment, and gradually increased to $82.36 \pm 1.22 \%, 61.41 \pm 8.80 \%$, and $55.99 \pm$ $10.28 \%$ after $6 \mathrm{~h}$ and to $90.74 \pm 1.57 \%, 82.85 \pm 4.52 \%$, and $75.79 \pm 6.12 \%$ after $12 \mathrm{~h}$ (Fig. 1B). The rate of excystment between non-irradiated and irradiated cysts was significantly different in the early excystment phase but over time the difference was not significantly different (Fig. 1B), similar to the results with wet cysts (Fig. 1A). In contrast, the excystment rate of irradiated dry cysts and irradiated-incubated dry cysts was not significantly different at all time points (Fig. 1B), indicating that cell repair mechanisms were not active in dry cysts under dry conditions (anhydrobiosis).

This paper described cell repair in the resting cysts and its absence in dry cysts. The cell condition of cysts (more than 1-week-old-cyst) which were used in this study must have been under cryptobiosis, because the mitochondrial membrane potential was reported to be lost (Fnadani et al. 2010, Sogame et al. 2014). Then, cells in the resting cysts show no or few features associated with life and are extremely tolerant to environmental stresses. Such cells might have developed energy-saving cell repair mechanisms and/or harbor stress-inducible factors for activating cell metabolism systems for cell repair. The resting cyst formation (encystment) and cryptobiosis also might be a cell recovery process, therefore resting cysts can remain stable for long periods of time.

Acknowledgements. We would like to express our deep gratitude to Mr. T. Takyu (National Institute of Agriculture and Food Re- 
search Organization) for his technical support with the irradiation experiments and to Dr. T. Furusawa (National Institute of Agriculture and Food Research Organization) for his support with the irradiation experiments. This research was financially supported by JSPS KAKENHI Grant Numbers JP19K16193 and JP16K18827, Sasagawa Scientific Research Grants \#24-407 and \#29-808, and a Narishige Zoological Science Award.

\section{REFERENCES}

Azam E. I., Jay-Gerin J. P., Pain D. (2012) Ionizing radiationinduced metabolic oxidative stress and prolonged cell injury. Cancer Lett. 327: 48-60

Campbell C., Romero D. P. (1998) Identification and characterization of the RAD51 gene from the ciliate Tetrahymena thermophila. Nucleic Acids Res. 26: 3165-3172

Clegg S. J. (2001) Cryptobiosis: a peculiar state of biological organization. Comp. Biochem. and Physiol. B 128: 613-624

Close D. M., Nelson W. H., Bernhard W. A. (2013) DNA Damage by the Direct Effect of Ionizing Radiation: Products Produced by Two Sequential One-Electron Oxidations. J. phys. chem. 117: $12608-12615$

DiRuggiero J., Santangelo N., Nackerdien Z., Ravel J., Robb F. T. (1997) Repair of extensive ionizing-radiation DNA damage at 95 degrees $\mathrm{C}$ in the hyperthermophilic archaeon Pyrococcus furiosus. J. Bacteriol. 179: 4643-4645

Funatani R., Kida A., Watoh T., Matsuoka T. (2010) Morphological events during resting cyst formation in the ciliate Colpoda cucullus. Protistlogy 6: 204-217

Gutiérrez J. C., Martín-González A. Matsusaka T. (1990) Towards a generalized model of encystment (cryptobiosis) in ciliates: a review and a hypothesis. BioSystems. 24: 17-24

Gutiérrez J. C., Callejas S., Borniquel S., Benítez L., MartínGonzález A. (2001) Ciliate cryptobiosis: a microbial strategy against environmental starvation. Int. Microbiol. 4: 151-157

Gutiérrez J. C., Díaz S., Ortega R., Martín-González A. (2003) Ciliate resting cyst walls: A comparative review. Recent Res. Devel. Microbiol. 7: 361-379

Hallwell B., Gutteridge J. (1999) Free Radicals in biology and medicine. Oxford University Press, Oxford

Imlay J. A., Linn S. (1988) DNA damage and oxygen radical toxicity. Science 240: 4857
Jung K., Lim S., Bahn Y. (2017) Microbial radiation-resistance mechanisms. J. Microbiol. 55: 499-507

Keilin D. (1959) The problem of anabiosis or latent life: history and current concept. Proc. Roy. Soc. Lond. B 150: 149-191

Richter J. R., Kasten B. B., Zinn K. R. (2016) Imaging and Adenoviral gene therapy. In Curiel DT (ed) Adenovital vectors for gene therapy. Elsevier, pp. 767-802

Roca A. I., Cox M. M. (1997) RecA protein: structure, function, and role in recombinational DNA repair. Prog. Nucleic Acid Res. Mol. Biol. 56: 129-222

Ryter S. W., Kim H. P., Hoetzel A., Park J. W., Nakahira K., Wang X., Choi A. M. Mechanisms of Cell Death in Oxidative Stress. Antioxid. Redox. Signal. 9: 49-89

Sogame Y., Kida A., Matsuoka T. (2011) Possible involvement of endocyst in tolerance of the resting cyst of Colpoda cucullus against HCl. Afr. J. Microbiol. Res. 5: 4316-4320

Sogame Y., Kojima K., Takeshita T., Kinoshita E., Funadani R., Matsuoka T. (2013) Excystment-Dependent Alteration of Protein Expression in Terrestrial Ciliate Colpoda cucullus. Microbes Environ. 28: 388-390

Sogame Y., Kojima K., Takeshita T., Kinoshita E., Matsuoka T. (2014) Identification of differentially expressed water-insoluble proteins in the encystment process of Colpoda cucullus by two-dimensional electrophoresis and LC-MS/MS analysis. J. Eukaryot. Microbiol. 61: 51-60

Slaveykova V., Sonntag B., Gutiérrez J. C. (2016) Stress and Protists: No life without stress. Eur. J. Protistol. 55: 39-49

Taylor C. V., Strickland A. G. R. (1936) Effects of high vacua and extreme temperatures on cysts of Colpoda cucullus. Physiol. Zool. 9: 15-26

Uspenskaya Z. I., Lozia-Lozinsky L. K. (1979) Antigen rearrangements in Colpoda maupasi cells after freezing at $-196^{\circ} \mathrm{C}$, and after shortwave ultraviolet irradiation. Cryobiology 16: 542549

Verni F., Rosati R. (2011) Resting cysts: a survival strategy in protozoa Ciliophora. Ital. J. Zool.78: 134-145

Received on $8^{\text {th }}$ April, 2019; revised on 28 ${ }^{\text {th }}$ June, 2019; accepted on $9^{\text {th }}$ July, 2019 